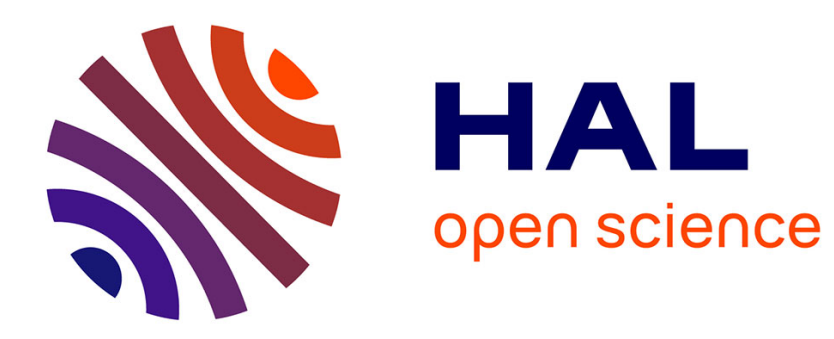

\title{
Polarization-sensitive full-field optical coherence tomography
}

Gael Moneron, Claude Boccara, Arnaud Dubois

\section{To cite this version:}

Gael Moneron, Claude Boccara, Arnaud Dubois. Polarization-sensitive full-field optical coherence tomography. Optics Letters, 2007, 32 (14), pp.2058. hal-00520535

\section{HAL Id: hal-00520535 \\ https://hal.science/hal-00520535}

Submitted on 24 Jan 2012

HAL is a multi-disciplinary open access archive for the deposit and dissemination of scientific research documents, whether they are published or not. The documents may come from teaching and research institutions in France or abroad, or from public or private research centers.
L'archive ouverte pluridisciplinaire HAL, est destinée au dépôt et à la diffusion de documents scientifiques de niveau recherche, publiés ou non, émanant des établissements d'enseignement et de recherche français ou étrangers, des laboratoires publics ou privés. 


\title{
Polarization-sensitive full-field optical coherence tomography
}

\author{
Gael Moneron, ${ }^{1}$ Albert-Claude Boccara,${ }^{1}$ and Arnaud Dubois ${ }^{2, *}$ \\ ${ }^{1}$ Laboratoire d'Optique Physique, École Supérieure de Physique et Chimie Industrielles, CNRS, UPR A0005, \\ 10 rue Vauquelin, F-75231 Paris Cedex 5, France \\ ${ }^{2}$ Laboratoire Charles Fabry de l'Institut d'Optique, CNRS, Université Paris-Sud, Campus Polytechnique, \\ RD 128, 91127 Palaiseau, France \\ *Corresponding author: arnaud.dubois@institutoptique.fr
}

Received March 8, 2007; revised May 9, 2007; accepted May 18, 2007; posted May 23, 2007 (Doc. ID 80862); published July 10, 2007

\begin{abstract}
We present a polarization-sensitive full-field optical coherence tomography system that can produce highresolution images of the linear retardance and reflectivity properties of biological media. En face images can be delivered at a frame rate of $3.5 \mathrm{~Hz}$ by combination of interferometric images acquired by two CCD cameras in an interference microscope illuminated with a tungsten halogen lamp. Isotropic spatial resolution of $\sim 1.0 \mu \mathrm{m}$ is achieved. The technique is demonstrated on ex vivo muscle tissues. (C) 2007 Optical Society of America

OCIS codes: $170.4500,260.5430,260.1440,120.5410,170.3880$.
\end{abstract}

Optical coherence tomography (OCT) is a technique of choice for noninvasive three-dimensional imaging of biological tissues with micrometer-scale resolution $[1,2]$. OCT measures the amplitude of the light backscattered by the object illuminated by a broadband source. Polarization-sensitive OCT (PS-OCT) is an extension of OCT that provides additional information on the polarization properties of the tissues. PSOCT can be performed in the time domain [3-7] or in the frequency domain $[8,9]$. The sensitivity advantage of frequency-domain OCT over time-domain OCT can be used either to shorten the acquisition time or to improve the signal-to-noise ratio. Many biological tissues exhibit birefringence related to various components such as collagen, myelin, and elastic fibers. PS-OCT can offer enhanced contrasts and specificity in structure identification. Conventional PS-OCT experimental setups require scanning the sample transversally to build up images. Fullfield OCT, also sometimes referred to as full-field optical coherence microscopy, was proposed a few years ago as an alternative method to perform ultrahighresolution OCT using a CCD camera to avoid lateral scanning and using a simple white-light source such as a tungsten halogen lamp [10-12]. We present in this paper a new full-field OCT technique that can also provide linear retardance measurements in real time.

The schematic of the experimental setup is represented in Fig. 1. It is based on a bulk Michelson interferometer with identical water-immersion microscope objectives in both arms. This configuration is referred to as a Linnik interference microscope [13]. A reference mirror with $2 \%$ reflectivity is realized by the interface between the polished surface of a $\mathrm{Y}_{3} \mathrm{Al}_{5} \mathrm{O}_{12}$ (YAG) crystal and water. Ultrastable highpower spatially and temporally incoherent illumination is achieved by using a $12 \mathrm{~V}, 100 \mathrm{~W}$ Köhler halogen illuminator with a stabilized DC power supply. Light is linearly polarized by a polarizer $(\mathrm{P})$ oriented at a $0^{\circ}$ angle and split into the reference and sample arms by a broadband polarization-insensitive beam splitter (BS). Light in the reference arm passes through an achromatic quarter-wave plate (AQWP) oriented at a $22.5^{\circ}$ angle to the incident polarization, is then reflected by a reference mirror, and passes through the AQWP again. Reference light is thus linearly polarized at a $45^{\circ}$ angle to the incident polarization. Light in the sample arm passes through an identical AQWP oriented at a $45^{\circ}$ angle, so that the sample is illuminated with circularly polarized light.

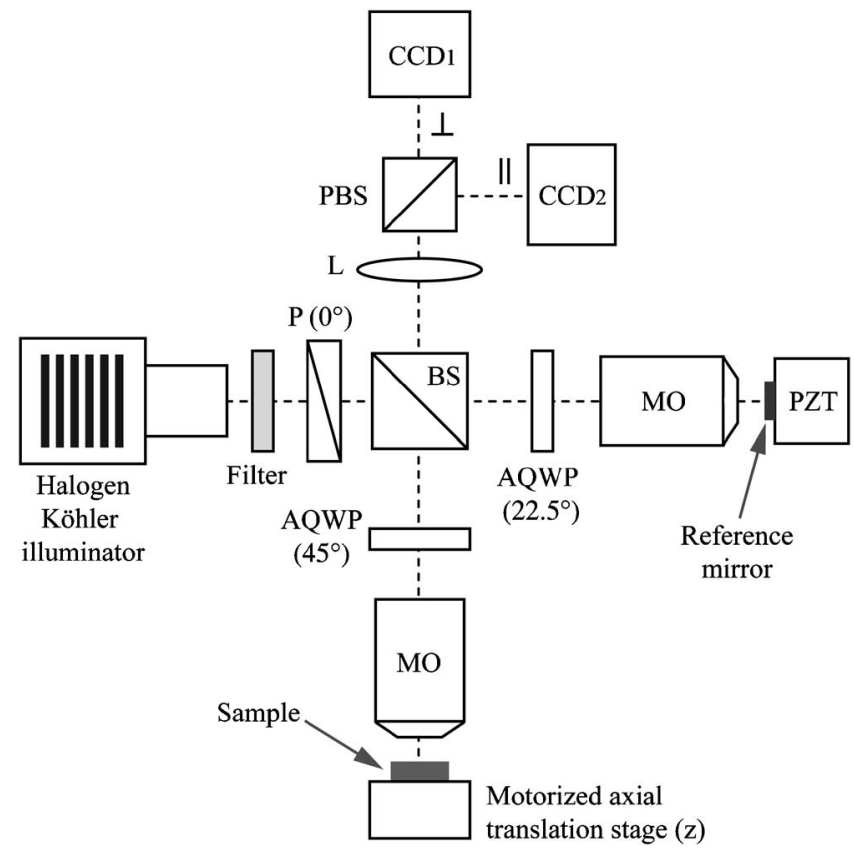

Fig. 1. Experimental arrangement. P, polarizer; BS, beam splitter (broadband, nonpolarizing); PBS, polarizing beam splitter (broadband); MO, microscope objective (water immersion, $\times 10,0.3 \mathrm{NA}) ; L$, achromatic doublet lens $(300 \mathrm{~mm}$ focal length). The reference mirror ( $2 \%$ reflectivity) oscillates at $3.5 \mathrm{~Hz}$. The synchronized CCD cameras are triggered at $14 \mathrm{~Hz}$ to acquire four images per modulation period. 
Returning from the sample and passing through the AQWP, light has an arbitrary (elliptical) polarization state due to the optical anisotropy properties of the sample. After recombination by the beam splitter, the sample and reference images interfere. The interferometric signal is split into two orthogonal polarization components by a polarizing beam splitter (PBS) oriented at $0^{\circ}(\|)$ and $90^{\circ}(\perp)$ angles to the incident polarization. The two resulting images are projected onto two CCD arrays (Dalsa 1M15, 1024 $\times 1024$ pixels, 12 bits) by an achromatic doublet lens with a $300 \mathrm{~mm}$ focal length. $2 \times 2$ binning is applied to increase the effective dynamic range of the CCD cameras. Because of the spectral response of the silicon-based CCDs and the use of a long-wave-pass filter, the effective spectrum of the illumination light has a width of $\Delta \lambda=300 \mathrm{~nm}$ (FWHM) centered at $\lambda$ $=750 \mathrm{~nm}$, which fits the bandwidth acceptance of the achromatic wave plates. The reference mirror is attached to a piezoelectric translation stage (PZT) to make it oscillate at the frequency $f=3.5 \mathrm{~Hz}$. This oscillation generates a sinusoidal phase modulation in the interferometer. The intensity on each pixel $(x, y)$ of the CCDs is then time modulated at the frequency $f$. The CCD cameras are triggered at $4 f=14 \mathrm{~Hz}$ and synchronized with the PZT oscillation. The CCD cameras capture four images per modulation period. An adjustable number $N$ of series of four images are accumulated in four buffers on the computer. By combining the four frames $E_{1}^{\perp}, E_{2}^{\perp}, E_{3}^{\perp}, E_{4}^{\perp}$, and $E_{1}^{\|}, E_{2}^{\|}, E_{3}^{\|}, E_{4}^{\|}$, acquired by $\mathrm{CCD}_{1}(\perp)$ and $\mathrm{CCD}_{2}(\|)$ respectively, according to

$$
\begin{gathered}
\Gamma^{\perp}=\left(E_{1}^{\perp}-E_{2}^{\perp}\right)^{2}+\left(E_{3}^{\perp}-E_{4}^{\perp}\right)^{2}, \\
\Gamma^{\|}=\left(E_{1}^{\|}-E_{2}^{\|}\right)^{2}+\left(E_{3}^{\|}-E_{4}^{\|}\right)^{2},
\end{gathered}
$$

we can show, using the Jones matrix formalism, that

$$
\Gamma^{\perp} \propto R \cos ^{2}(\phi), \quad \Gamma^{\|} \propto R \sin ^{2}(\phi),
$$

where $\phi$ denotes the single-pass phase retardation due to the object birefringence and $R$ is the object reflectivity. Phase-retardation images $\phi(x, y)$ are then obtained by calculating the ratio $\Gamma^{\| \prime} / \Gamma^{\perp}$. Polarizationindependent tissue reflectivity images $R(x, y)$ can also be obtained from the sum $\Gamma^{\perp}+\Gamma^{\|}$. Data acquisition, computation, and display of the computed images are performed by home-written Visual C++ software. Images are produced at a frame rate of several hertz, depending on the accumulated image number $N(3.5 \mathrm{~Hz}$ for $N=1)$.

Conventional PS-OCT requires a large depth of field to avoid focus adjusting while acquiring the axial dimension of the image. Very low numerical aperture (NA) objectives are therefore used, which limits the transverse resolution $(10-20 \mu \mathrm{m})$. Our fullfield OCT technique produces en face tomographic images, which eliminates the limitation to such low NA values. We use here water-immersion microscope objectives with a moderate NA value of 0.3 , which yields a theoretical transverse resolution of $\sim 1 \mu \mathrm{m}$ without introducing detectable polarization artifacts that could be present with a higher NA. The axial resolution of the images is determined here by the effective coherence length of the illumination source and not by the objective NA. In a medium with refractive index $n=1.33$ (water), the theoretical axial resolution is $\Delta z=1 \mu \mathrm{m}$. Since biological tissues consist mainly of water, the use of identical waterimmersion microscope objectives minimizes dispersion mismatch when imaging deep inside the tissues. Nevertheless, residual dispersion mismatches and optical aberrations due to refractive index inhomogeneities within the tissues inevitably cause a slight degradation of the axial and transverse resolutions compared with the theoretical value of $1 \mu \mathrm{m}$.

The instrument accuracy for linear retardance measurements was tested by measuring the phase retardation introduced by a Babinet compensator placed into the sample arm between the the quarter wave-plate (AQWP) and the microscope objective (MO). A glass plate with appropriate thickness was placed in the other arm of the interferometer to compensate for the dispersion. A phase retardation varying between $0^{\circ}$ and $225^{\circ}$ was generated by the calibrated Babinet compensator. Figure 2 compares the measured phase retardation with the true phase retardation introduced by the compensator. The RMS error was $3^{\circ}$ ( $7 \%$ average error over the whole scale). The error may result from the calculations, which assume a monochromatic illumination. A rotation of the Babinet compensator in the plan orthogonal to the optical axis had no effect on the measured value of the phase retardation, which was a confirmation of the insensitivity of the setup to the object orientation. When imaging a birefringent object with a microscope objective, the angle between the optical rays and the birefringence optic axis is not as well defined. It has recently been shown that a substantial discrepancy between measured retardance and true retardance can be induced by variations in this angle [14]. We also point out that the phase retardation at a depth $z$ under the object surface does not represent a strictly depth-resolved measurement [15], but the accumulated linear retardance, i.e., the linear retardance integrated along the depth $z$ and over the optical ray angle distribution.

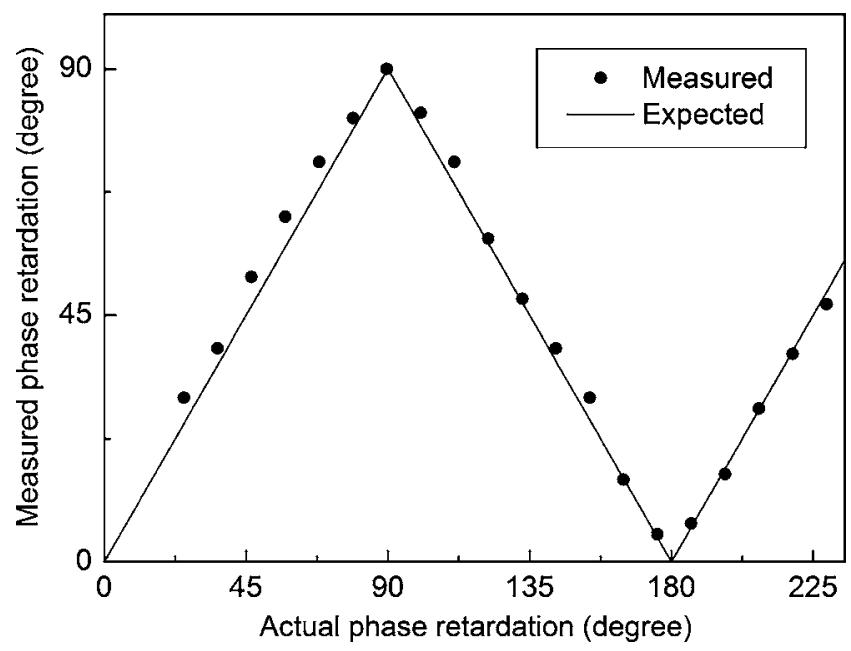

Fig. 2. Measured versus actual phase retardation introduced by a calibrated Babinet compensator. 
To illustrate the system performances for biomedical applications, we imaged fresh muscle tissues extracted from a shrimp tail. The tissues were placed in a tank filled with phosphate-buffered saline (PBS, $\mathrm{pH} 7$ ) for preservation. En face oriented images are shown in Fig. 3 using 256 gray levels. Linear retardance varies from $0^{\circ}$ (black) to $90^{\circ}$ (white). Intensity, on a logarithmic scale, varies from $-90 \mathrm{~dB}$ (black) to $-45 \mathrm{~dB}$ (white). Couples of images were acquired at two different depths within the tissues, separated by $70 \mu \mathrm{m}$. Intensity images and phase images exhibit different and uncorrelated contrasts. One can notice a dark area on Fig. 3(c) that becomes bright on Fig $3(\mathrm{~d})$, indicating a variation of $\sim 70^{\circ}$ in phase retardation, whereas the gray levels in some other areas remain almost unchanged. This clearly reveals optical anisotropy inhomogeneities in the tissues.
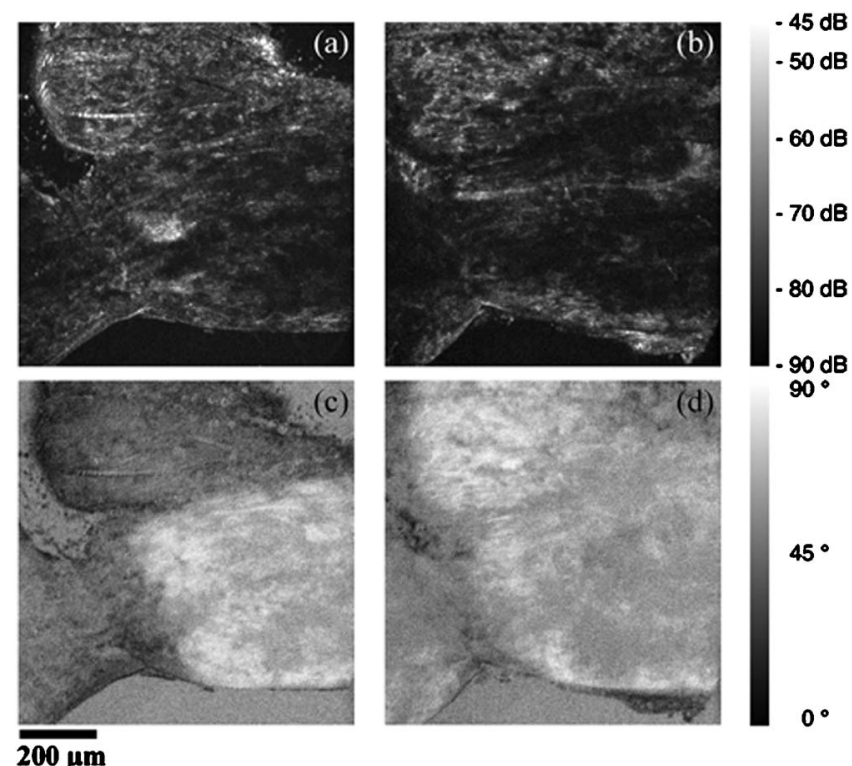

Fig. 3. Polarization-sensitive full-field OCT images of shrimp tail muscles. (a), (b) are en face intensity-based images acquired at depths of 30 and $100 \mu \mathrm{m}$, respectively. (c), (d) are the corresponding linear-birefringence-induced phase-retardation images. The couples (a), (c) and (b), (d) illustrate the two different contrasts.
In summary, we have developed a polarizationsensitive full-field OCT system that produces images of biological media with both intensity-based and linear-retardance-based contrasts. Compared with conventional full-field OCT, polarization-sensitive full-field OCT provides additional information related to the object polarization properties. With a moderate increase in experimental setup complexity and price, polarization full-field OCT offers larger potentialities for biomedical applications.

\section{References}

1. D. Huang, E. A. Swanson, C. P. Lin, J. S. Schuman, W. G. Stinson, W. Chang, M. R. Hee, T. Flotte, K. Gregory, C. A. Puliafito, and J. G. Fujimoto, Science 254, 1178 (1991).

2. A. F. Fercher, J. Biomed. Opt. 1, 157 (1996).

3. M. R. Hee, D. Huang, E. A. Swanson, and J. G. Fujimoto, J. Opt. Soc. Am. B 9, 903 (1992).

4. J. F. de Boer, T. E. Milner, M. J. C. van Gemert, and J. S. Nelson, Opt. Lett. 22, 934 (1997).

5. K. Schoenenberger, B. W. Colston, J. Duncan, J. Maitland, L. B. D Silva, and M. J. Everett, Appl. Opt. 37, 6026 (1998).

6. B. Cense, T. C. Chen, B. H. Park, M. C. Pierce, and J. F. de Boer, Opt. Lett. 27, 1610 (2002).

7. S. Jiao and L. V. Wang, Opt. Lett. 27, 101 (2002).

8. Y. Yasuno, S. Makita, Y. Sutoh, M. Itoh, and T. Yatagai, Opt. Lett. 27, 1803 (2002).

9. B. H. Park, M. C. Pierce, B. Cense, S. H. Yun, M. Mujat, G. J. Tearney, B. E. Bouma, and J. F. de Boer, Opt. Express 13, 3931 (2005).

10. L. Vabre, A. Dubois, and A. C. Boccara, Opt. Lett. 27, 530 (2002).

11. A. Dubois, K. Grieve, G. Moneron, R. Lecaque, L. Vabre, and A. C. Boccara, Appl. Opt. 43, 2874 (2004).

12. A. Dubois, G. Moneron, and A. C. Boccara, Opt. Commun. 266, 738 (2006).

13. A. Dubois, L. Vabre, A. C. Boccara, and E. Beaurepaire, Appl. Opt. 41, 805 (2002).

14. N. Ugryumova, S. V. Gangnus, S. J. Matcher, Opt. Lett. 31, 2305 (2006).

15. S. Guo, J. Zhang, L. Wang, J. S. Nelson, and Z. Chen, Opt. Lett. 29, 2025 (2004). 